\title{
Luminescent properties of fine-dispersed self-propagating high-temperature synthesized ZnS:Cu,Mg
}

\author{
Yu.Yu. Bacherikov ${ }^{1}$, A.G. Zhuk ${ }^{1}$, R.V. Kurichka ${ }^{1}$, O.B. Okhrimenko ${ }^{1}$, A.V. Gilchuk ${ }^{2}$, O.V. Shcherbyna ${ }^{2}$, \\ M.V. Herkalyuk ${ }^{2}$ \\ ${ }^{1}$ V. Lashkaryov Institute of Semiconductor Physics, NAS of Ukraine \\ 41, prospect Nauky, 03028 Kyiv, Ukraine; e-mail: Yuyu@isp.kiev.ua \\ ${ }^{2}$ National Technical University of Ukraine "Igor Sikorsky Kyiv Polytechnical Institute” \\ 37, prospect Peremogy, 03056 Kyiv, Ukraine
}

\begin{abstract}
The influence of magnesium impurities on luminescent properties of $\mathrm{ZnS}: \mathrm{Cu}, \mathrm{Mg}$ using obtained by self-propagating high-temperature synthesis (SHS) has been investigated. Special attention was paid to changes of photoluminescence spectra caused by relaxation processes in $\mathrm{ZnS}: \mathrm{Cu}, \mathrm{Mg}$-SHS. It was shown that introduction of magnesium into $\mathrm{ZnS}$ :Cu-SHS leads to a change in symmetry of $\mathrm{ZnS}$ crystal lattice. It leads to relaxation quenching the photoluminescence bands caused by presence of copper impurities in $\mathrm{ZnS}$.
\end{abstract}

Keywords: self-propagating high-temperature synthesis, photoluminescence spectra, luminescence excitation spectra, electron microscopy.

Manuscript received 12.01.17; revised version received 26.04.17; accepted for publication 14.06.17; published online 18.07.17.

\section{Introduction}

The increasing flow of information stimulates studies of materials that can be used as luminophores for basic components of display devices [1-3]. At the same time, luminescent characteristics of light-emitting materials largely depend on the material structure $[4,5]$, ratio of impurities acting as luminescence activators and coactivators $[6,7]$, etc. Studies of the materials obtained using unconventional methods, such as SHS, are of particular interest. Using SHS can reduce the cost of obtained luminophores, because this method is a lowcost technology.

In almost all studies of luminophores, the main task is to increase the intensity of radiation and possibility of using the obtained material in electroluminescent devices. In [8], it was shown improvement of electroluminescent characteristics in thin-film devices based on $\mathrm{ZnS}: \mathrm{Cu}, \mathrm{Mn}$ after doping $\mathrm{MgF}_{2}$ and $\mathrm{MgS}$. Also, increasing the intensity of photoluminescence (PL) after introduction of $\mathrm{MgS}$ or $\mathrm{MgCl}_{2}$ in defined concentration was noted [8].

At the same time, the resistance to degradation of luminophores is a necessary condition for their successful use. Most of luminophores looses their efficiency, which may be related both to valence change caused by oxidation, and to degradation of crystal lattice. In the second case, atoms diffuse through material and react with ambient matter. The results of degradation were not only decreasing the quantum efficiency of luminophore, but also changing the spectral characteristics of its luminosity.

The goal of this work was to study the influence of magnesium impurities that were introduced into $\mathrm{ZnS}$ as activator and co-activator in fine-dispersed $\mathrm{ZnS}: \mathrm{Cu}$ obtained using the SHS method, and time evolution of luminescent characteristics of obtained luminophores. 


\section{Materials and methods}

Fine-dispersed undoped ZnS-SHS, Mg-doped ZnS:Mg and doped with magnesium and copper $\mathrm{ZnS}: \mathrm{Cu}, \mathrm{Mg}$ were obtained using SHS. Magnesium and copper doping was carried out by adding $\mathrm{Cu}$ and $\mathrm{Mg}$ chlorides directly in the process of synthesis. For synthesis, $\mathrm{Zn}$ and $\mathrm{S}$ were taken in the stoichiometric ratio. Concentration of $\mathrm{Cu}$ was close to $1.2 \mathrm{wt} . \%$. For synthesis of $\mathrm{ZnS}: \mathrm{Mg}$, the concentration of $\mathrm{Mg}$ was $\sim 1.2 \mathrm{wt} . \%$. For synthesis of $\mathrm{ZnS}: \mathrm{Cu}, \mathrm{Mg}$, the amount of $\mathrm{MgCl}_{2}$ in the charge was $\sim 5$ wt. $\%$. Charge materials were analytical grade.

Photoluminescence spectra were registered at room temperature by using the spectrometer SDL-2.

Investigation of particle sizes and morphology was carried out using the method of scanning electron microscopy with the device REM-106 I. Samples were investigated using the accelerating voltage $20 \mathrm{keV}$ in the regime of backscattered electrons.

Measurements of elemental composition were performed using energy-dispersive X-ray spectroscopy (EDS).

\section{Experimental results and discussion}

Electron microscopy study of $\mathrm{ZnS}: \mathrm{Cu}, \mathrm{Mg}$-SHS showed that the synthesized powders consist of two fractions. One fraction consists of large particles with dimensions up to several decades of micrometers. The second fraction consists of particles of micron and submicron sizes (Fig. 1a). The minimum Ferret diameter was chosen as a characteristic particle size. The histogram of particle sizes distribution is shown in Fig. 1b. The function of distribution was approximated by lognormal low and, according to this approximation, the average particle size was $1.32 \pm 0.01 \mu \mathrm{m}$.

According to EDS measurements (Fig. 2), elemental composition of fine-dispersed $\mathrm{ZnS}: \mathrm{Cu}, \mathrm{Mg}$ SHS is close to the stoichiometric one: $\mathrm{Zn}_{48.8} \mathrm{~S}_{49.0} \mathrm{Cu}_{0.7} \mathrm{Mg}_{1.5}$.
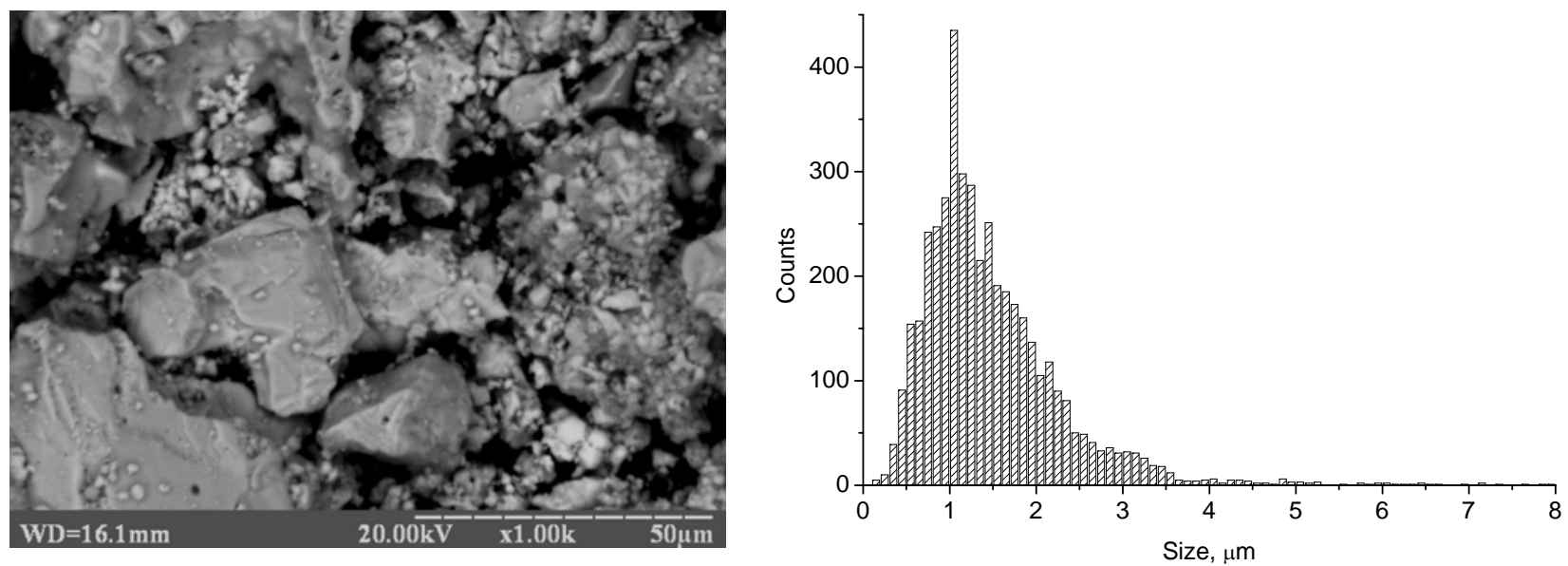

Fig. 3a represents PL spectra of ZnS-SHS, $\mathrm{ZnS}: \mathrm{Mg}$-SHS and $\mathrm{ZnS}: \mathrm{Cu}, \mathrm{Mg}$-SHS. As can be seen from Fig. 3a, curves 1 and 2 in the spectra of undoped $\mathrm{ZnS}-\mathrm{SHS}$ and $\mathrm{ZnS}: \mathrm{Mg}$ are almost identical by their spectral composition. This means that luminescence of both powders is self-activated and caused by identical centers. Slight broadening the PL line in the area of long waves can be associated with disturbance in lattice of $\mathrm{ZnS}$ during the process of introducing the impurity with very different ionic radius.

The PL spectrum of undoped ZnS-SHS is a broad line in the area of 400 to $650 \mathrm{~nm}$ with $\lambda_{\max } \sim 505 \mathrm{~nm}$. This band is complicated and consists of several individual components. Decomposition of the PL spectrum of ZnS-SHS into components is presented in Fig. 3b. The PL bands with $\lambda_{\max } \sim 455-465 \mathrm{~nm}$ was related to native defects and their complexes that may complexes are centers of self-activated (SA) luminescence. According to [9, 10], SA-luminescence of undoped $\mathrm{ZnS}$ consists of range of closely located and, in general, overlapped bands of PL related with different defects (Fig. 3b).

Investigation of spectral composition of $\mathrm{ZnS}: \mathrm{Cu}, \mathrm{Mg}-\mathrm{SHS}$ PL spectra, registered immediately after synthesis, showed a significant difference in comparison with the spectrum of undoped ZnS-SHS and ZnS:Mg-SHS. As can be seen from Fig. 3a, curve 3, spectrum of $\mathrm{ZnS}: \mathrm{Cu}, \mathrm{Mg}$ that was registered immediately after synthesis is a broad asymmetric sub-band with $\lambda_{\max } \sim 530 \mathrm{~nm}$. This band is complicated and consists of at least three individual components with $\lambda_{\max } \sim 450, \sim 500$ and $\sim 520 \mathrm{~nm}$. It is well known that PL band of $\mathrm{ZnS}: \mathrm{Cu}$ in the blue-green region is complex, and usually is a superposition of several sub-bands related to copper dopant and native defects of $\mathrm{ZnS}$. The nature of the luminescent centers responsible for the blue and green lines is $\mathrm{ZnS}$ was studied in sufficient detail in [11-18]. include co-activator and oxygen $[9,10]$. These

Fig. 1. a) Electron microscopic image of $\mathrm{ZnS}: \mathrm{Cu}, \mathrm{Mg}-\mathrm{SHS}$ powder. b) Size distribution of particles in $\mathrm{ZnS}: \mathrm{Cu}, \mathrm{Mg}$-SHS. 


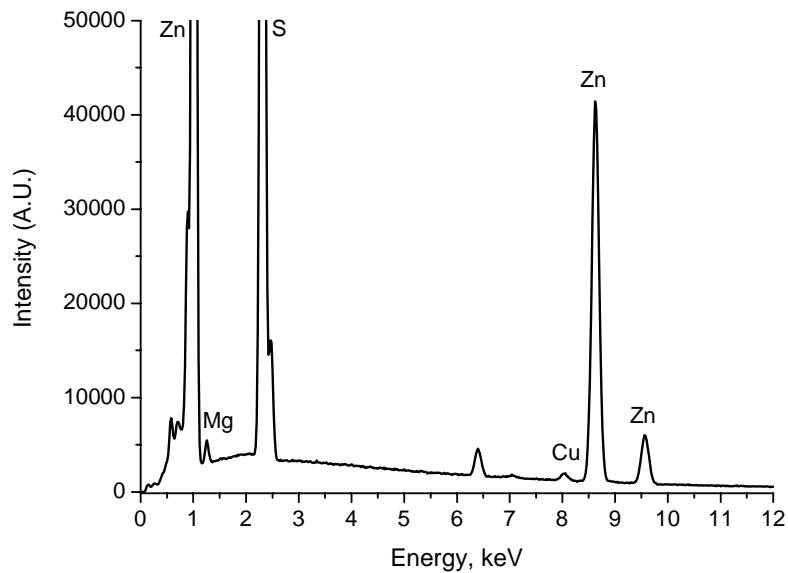

Fig. 2. EDS spectrum of fine-dispersed $\mathrm{ZnS}: \mathrm{Cu}, \mathrm{Mg}$-SHS.
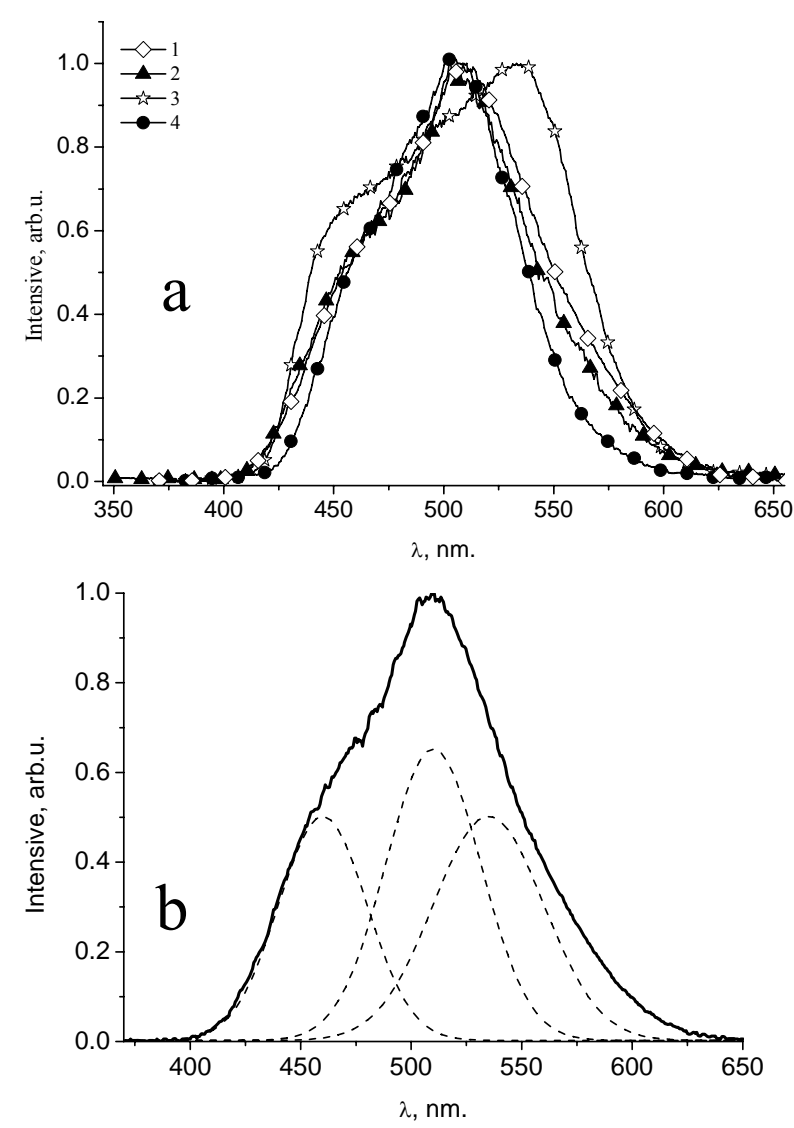

Fig. 3. a) PL spectra of: ZnS-SHS (1), ZnS:Mg-SHS (2), $\mathrm{ZnS}: \mathrm{Cu}, \mathrm{Mg}$-SHS (3) immediately after synthesis, $\mathrm{ZnS}: \mathrm{Cu}, \mathrm{Mg}$ SHS 7 days after synthesis (4); b) decomposition of ZnS-SHS spectrum into components.

Authors [11-17] showed that the center responsible for the appearance of $\mathrm{Cu}$ green line was insulated copper ion that replaced the zinc one in the lattice of $\mathrm{ZnS}$. It was determined that symmetry of this center is not less than that of the regular lattice point in cubic or hexagonal lattice of $\mathrm{ZnS}$. At the same time, this center doesn't include co-activator. The blue band was related with formation of donor-acceptor type associations $\mathrm{Cu}_{i}-\mathrm{Cu}_{\mathrm{Zn}}[18]$.
The PL spectrum of $\mathrm{ZnS}: \mathrm{Cu}, \mathrm{Mg}$-SHS undergoes great changes in 7 days after synthesis (Fig. 3a, curve 4). PL bands caused by copper dopant and presented in Fig. 3a, curve 3, are almost absent in the spectrum registered in 7 days after synthesis (Fig. 3a, curve 4). Comparison of the PL spectrum of $\mathrm{ZnS}: \mathrm{Cu}, \mathrm{Mg}-\mathrm{SHS}$ registered a week after synthesis and the PL spectrum of undoped ZnS-SHS showed that PL spectra in these cases can be related to the centers of radiative recombination, which have similar nature. At the same time, the PL band with the maximum in the range of $500 \mathrm{~nm}$, which is related with self-activated $\mathrm{PL}$ in $\mathrm{ZnS}$, is dominant in the spectrum of pure $\mathrm{ZnS}-\mathrm{SHS}, \mathrm{ZnS}: \mathrm{Cu}, \mathrm{Mg}$-SHS and ZnS:Mg-SHS (Fig. 3a).

These data indicate that centers of radiative recombination which includes copper are destroyed during the relaxation processes in material. Probably, it is caused by increasing in the degree of $\mathrm{ZnS}$ lattice deformation in processes of magnesium introduction, because the ionic radius of $\mathrm{Mg}$ is much less than that of $\mathrm{Zn}$ and $\mathrm{Cu}$. According to [19], Mg ions can partially fill tetrahedral interstitial sites or replace $\mathrm{Zn}$ in $\mathrm{ZnS}$ lattice. The volume of the unit cell, in which $\mathrm{Mg}$ is inserted, decreases due to shorter ion radius of $\mathrm{Mg}$. Consequently, mechanical stress and deformation of $\mathrm{ZnS}$ lattice occur. Furthermore, introduction of magnesium can change the phase ratio in $\mathrm{ZnS}$ [19]. It is well known $[11,20]$ that introduction of copper usually stabilizes the cubic phase, but introduction of magnesium stabilizes the hexagonal phase, according to [21]. Therefore, since both copper centers include $\mathrm{Cu}_{\mathrm{Zn}}$, it is quite possible that simultaneous decrease of green and blue bands is caused by copper shifting from the main position into the interstitial site due to deformation or to the change of lattice symmetry. Perhaps, this process will be accompanied by dropping out of $\mathrm{Cu}$ as separate fraction.

It should be mentioned that SHS - is physicalchemical process that proceeds in extreme conditions at high temperature and with a high rate of heating the substance in a wave of combustion [22, 23]. These factors lead to formation of several phases of material (with different crystal structure, character of bonds, symmetry, etc.) during the process of synthesis in wide temperature and pressure ranges. All this contributes to the appearance of unstable structural states in material.

Therefore, at the beginning of introduction of $\mathrm{MgCl}_{2}$ into the charge, magnesium compounds lead to mass transfer between particles of $\mathrm{ZnS}$, i.e. act as a flux $[21,24,25]$. According to $[4,11]$, it may contribute to introduction of an activator (copper or some other dopants) into lattice of luminophore. In the further relaxation processes (especially if synthesis conditions facilitate the formation of unstable structural states or phases), presence of magnesium promotes deformation processes, which leads to changes in symmetry of $\mathrm{ZnS}$ crystal lattice. It becomes a reason for quenching the PL bands, which is caused by presence of copper impurities. 
References

1. Mirhabibi A.R., Rabiee M., Aghababazadeh R., Moztarzadeh F., Hesaraki S. Preparation of and photo- and electroluminescence characteristics of $\mathrm{ZnS}: \mathrm{Cu}$ phosphor. Pigm. Resin Technol. 2003. 32, No. 6. P. 358-363.

2. Bang J., Abrams B., Wagner B., and Holloway P.H. Effects of coatings on temporal cathodoluminescence quenching in $\mathrm{ZnS}: \mathrm{Ag}, \mathrm{Cl}$ phosphors. J. Appl. Phys. 2004. 95, No. 12. P. 7873-7880.

3. Park J.H., Lee S.H., Kim J.S., Kwon A.K., Park H.L., Han S.D. White-electroluminescent device with $\mathrm{ZnS}: \mathrm{Mn}, \mathrm{Cu}, \mathrm{Cl}$ phosphor. J. Lumin. 2007. 126, No. 2. P. 566-570.

4. Sychov M.M., Ogurtsov K.A., Lebedev T.V. et al. Effect of the $\mathrm{Cu}$ content and $\mathrm{ZnS}$ treatment on the characteristics of synthesized $\mathrm{ZnS}:(\mathrm{Cu}, \mathrm{Cl})$ electroluminescent phosphors. Semiconductors. 2012. 46, No. 5. P. 696-700.

5. Ummartyotin S., Bunnak N., Juntaro J., Sain M., Manuspiya H. Synthesis and luminescence properties of $\mathrm{ZnS}$ and metal (Mn, $\mathrm{Cu}$ )-doped- $\mathrm{ZnS}$ ceramic powder. Solid State Sci. 2012. 14, No. 3. P. 299-304.

6. Zhang W., Zeng X., Liu H. and Lu J. Synthesis and investigation of blue and green emissions of $\mathrm{ZnS}$ ceramics. J. Lumin. 2013. 134. P. 498-503.

7. Nien Y.-T., Chen I.G., Hwang Ch.-Sh. and Chu Sh.G. Copper concentration dependence of structure, morphology and optical properties of $\mathrm{ZnS}: \mathrm{Cu}, \mathrm{Cl}$ phosphor powder. J. Phys. Chem. Solids. 2008. 69, No. 2-3. P. 366-371.

8. Yuan J., Haneman D. and Gong B. Electroluminescence from $\mathrm{ZnS}: \mathrm{MnCl}_{2}$ thin film devices co-doped with $\mathrm{MgF}_{2}$ or $\mathrm{MgS}$. Mater. Res. Innovations. 1999. 2, No. 4. P. 223-226.

9. Morozova N.K., Mideros D.A., Danilevich N.D. Absorption, luminescence excitation, and infrared transmittance spectra of $\mathrm{ZnS}(\mathrm{O})-\mathrm{ZnSe}(\mathrm{O})$ crystals in the context of the band anticrossing theory. Semiconductors. 2009. 43, No. 2. P. 162-167.

10. Morozova N.K., Karetnikov I.A., Blinov V.V., Gavrishchuk E.M. A study of luminescence centers related to copper and oxygen in $\mathrm{ZnSe}$. Semiconductors. 2001. 35, No. 1. P. 24-32.

11. Aven M. and Prener J.S. Physics and Chemistry of II-VI Compounds. N. Y., North-Holland Publishing Company, Amsterdam, 1967.

12. Peng W.Q., Cong Y.W., Qui S.C. and Wang Z.Y. Synthesis and photoluminescence of $\mathrm{ZnS}: \mathrm{Cu}$ nanoparticles. Opt. Mater. 2006. 29, No. 2-3. P. 313-317.

13. Que W., Zhou Y., Lam Y.L., Chan Y.C., Kam C.H. Photoluminescence and electroluminescence from copper doped zinc sulphide nanocrystals/polymer composite. Appl. Phys. Lett. 1998. 73, No. 19. P. 2727-2729.

14. Bacherikov Yu.Yu., Golovina I.S. and Kitsyuk N.V. Thermal transformations in $\mathrm{ZnS}$ in the course of doping with $\mathrm{CuCl}$. Phys. Solid State. 2006. 48, No. 10. P. 1872-1877.

15. Riehl N. and Sizmann R. Luminescence of Organic and Inorganic Materials, Eds. H.P. Kallmann, G.M. Spruch. Wiley, New York, London, 1962, P. 344 354.

16. Urabe K., Shionoya Sh. and Suzuki A. Polarization of the blue-copper luminescence in $\mathrm{ZnS}$ crystals. $J$. Phys. Soc. Jpn. 1968. 25, No. 6. P. 1611-1617.

17. Morozova N.K., Mideros D.A., Galstian V.G., Gavrischuk E.M. Specific features of luminescence spectra of $\mathrm{ZnS}: \mathrm{O}$ and $\mathrm{ZnS}: \mathrm{Cu}(\mathrm{O})$ crystals in the context of the band anticrossing theory. Semiconductors. 2008. 42, No. 9. P. 1023-1029.

18. Markevich I., Zhuk A., Stara T., Bacherikov Yu., Korsunska N. About the origin of center responsible for $\mathrm{Cu}$-related blue emission band in $\mathrm{ZnS}: \mathrm{Cu}$. J. Lumin. 2014. 145. P. 71-73.

19. Reddy D.A., Kim D.H., Rhee S.J., Lee B.W. and Liu C. Tunable blue-green-emitting wurtzite $\mathrm{ZnS}: \mathrm{Mg}$ nanosheet-assembled hierarchical spheres for near-UV white LEDs. Nanoscale Res. Lett. 2014. 9, No. 1. P. 20.

20. Bacherikov Yu., Kuchuk A., Zhuk A., Polischuk Yu., Kladko V., Kryshtab T., Korsunska N. Correlation between luminescent characteristics and phase composition of $\mathrm{ZnS}: \mathrm{Cu}$ powder prepared by self-propagating high temperature synthesis. $J$. Lumin. 2014. 145. P. 970-975.

21. Ryu S.H., Kim W.K. and Lee S.E. Luminescence property of $\mathrm{ZnS}: \mathrm{Mn}, \mathrm{Mg}$ phosphor with excitation of plasma blue light source. Trans. Electr. Electron. Mater. 2013. 14, No. 1. P. 24-27.

22. Self-propagating High-temperature Synthesis of Materials. Ed. A.A. Borisov, L. De Luca, A.G. Merzhanov. New York: Taylor and Francis, 2002.

23. Aruna S.T., Mukasyan A.S. Current opinion in solid state and materials science. Curr. Opin. Solid State Mater. Sci. 2008. 12, No. 3-4. P. 44-50.

24. Sychov M.M., Zagranichek A.L., Ogurtsov K.A., Bakhmetjev V.V., Tsiplukhina A.M., Radomskaya L.N. Effect of $\mathrm{Mg}$ on properties of $\mathrm{Zn}_{\mathrm{x}} \mathrm{Mg}_{1-\mathrm{x}} \mathrm{S}: \mathrm{Cu}$ phosphor. Proc. 29-th Intern. Display Res. Conf., Eurodisplay 2009, Rome, P. 251-252.

25. Inoue R., Kitagawa M., Nishigaki T., Morita D., Ichino K., Kobayashi H., Ohishi M., Saito H. Growth and luminescence of $\mathrm{Zn}_{\mathrm{x}} \mathrm{Mg}_{1-\mathrm{x}} \mathrm{S}$ :Mn ternary compound crystal films. J. Cryst. Growth. 1999. 198/199. P. 1196-1204. 